\title{
Obtenção e Caracterização de Materiais Argilosos Quimicamente Ativados para Utilização no Descoramento de Óleo Vegetal
}

\author{
Edson L. Foletto ${ }^{\# a}$, Cristina Volzone ${ }^{*}{ }^{b}$, Ayres F. Morgado ${ }^{a}$, \\ Luismar M. Porto ${ }^{a}$ \\ ${ }^{a}$ Departamento de Engenharia Química e Engenharia de Alimentos, Universidade \\ Federal de Santa Catarina, C.P. 476, 88040-900 Florianópolis - SC, Brasil \\ ${ }^{\mathrm{b}}$ Centro de Tecnología de Recursos Minerales y Cerámica (CETMIC), C.C. 49, Cno \\ Centenario y 506 (1897) M.B. Gonnet, Prov. Buenos Aires, Argentina
}

Received: February 1, 2001; Revised: June 26, 2001

\begin{abstract}
A natural bentonite sample from Argentina was activated by sulfuric acid in different concentrations (20 and $40 \mathrm{wt} \%$ ) and different contact time (120 and $210 \mathrm{~min}$ ), at the same temperature $\left(90{ }^{\circ} \mathrm{C}\right)$. The ratio of the mass of clay to the volume of acid solution was 1:10 (w/v). These materials were tested to verify its bleaching (decolorization) capacity of soybean oil, which was compared to a standard commercial bleaching material Fulmont Premiere. Differential thermal analysis and thermogravimetric techniques, infrared spectrometry and chemical analysis showed that the acid activation modified the clay material structural properties. Bleaching capacity was found to be dependent on the acid concentration and treatment time used. The activated Argentine material showed superior bleaching performance compared to the commercial clay used by vegetable oil refiners.
\end{abstract}

Keywords: bentonite, acid activation, decolorization

\section{Introdução}

Devido às suas propriedades catalíticas e adsortivas, as argilas bentoníticas ativadas são empregadas industrialmente como catalisadores, suportes catalíticos e adsorventes $^{1}$. Elas têm sido usadas como catalisadores ácidos e suportes catalíticos em diversas reações orgânicas de considerável interesse industrial ${ }^{2,3}$ e têm sido largamente aplicadas em indústrias de papel, óleo mineral e indústria de alimentos $^{4,5,6}$. Entretanto, em termos de consumo, o uso mais importante desse material é na purificação, descoramento e estabilização de óleos vegetais ${ }^{7}$. Existem inúmeros trabalhos na literatura que tratam da ativação ácida de argilas. Volzone et al. ${ }^{8}$ realizaram um estudo de ativação ácida de um material esmectítico argentino, da Província de San Juan, de modo a estabelecer-se as condições ótimas em escala de laboratório, em termos de tempo de tratamento, relação sólido/ácido e concentração de ácido. O tratamento ácido em três diferentes argilas esmectíticas argentinas (amostras da Província de Río Negro, San Juan e Neuquén) foi avaliado posteriormente ${ }^{9}$. Morgado ${ }^{10}$ realizou um es-

*e-mail: volzcris@ netverk.com.ar

\#e-mail: edson@enq.ufsc.br

Trabalho apresentado no $14^{\circ} \mathrm{CBECIMAT,} \mathrm{Águas} \mathrm{de} \mathrm{São} \mathrm{Pedro,} \mathrm{Dezem-}$ bro de 2000 . tudo de ativação de bentonitas de Lages/SC - Brasil e verificou que as mesmas desenvolveram poder descorante para óleos vegetais comparável ao das argilas comerciais. No trabalho de Souza Santos ${ }^{11}$, é apresentada uma revisão sobre o estudo de ativação ácida em argilas esmectíticas brasileiras. A capacidade adsortiva desses materiais é aumentada significativamente por tratamento com ácidos fortes. Os ácidos geralmente utilizados são o sulfúrico e o clorídrico. $\mathrm{O}$ ataque ácido modifica a estrutura dos materiais argilosos ${ }^{12-15}$. A ativação promove uma dissolução parcial da argila e é caracterizada por uma substituição inicial de cátions interlamelares por $\mathrm{H}^{+16}$, seguida pela dissolução das folhas octaédricas e tetraédricas e subsequente lixiviação dos cátions estruturais ${ }^{17,18}$.

O presente trabalho tem por objetivo demonstrar que a argila argentina pode ser ativada por tratamento com ácido sulfúrico e adquirir poder descorante para óleo de soja equivalente ao de uma argila ativada comercial usada como referência. 


\section{Materiais e Métodos}

\subsection{Material argiloso}

Um quilograma de argila natural seca e moída, proveniente de Mendoza (Argentina), foi passada totalmente por peneira 200 mesh e utilizada para os ensaios. A amostra, denominada $\mathrm{K}$, foi caracterizada em um trabalho prévio ${ }^{15}$ e corresponde a uma bentonita formada por montmorilonita e beidelita contendo como impurezas o quartzo e o feldspato.

\subsection{Tratamento ácido}

Utilizou-se ácido súlfúrico P.A. Preparou-se uma suspensão de $10 \%$ (p/v) de argila em solução ácida aquosa para os ensaios de ativação. Para isso, utilizou-se um balão de três bocas com agitação, refluxo e medida de temperatura. $\mathrm{O}$ aquecimento foi feito com manta elétrica e a temperatura usada nos ensaios foi de $90{ }^{\circ} \mathrm{C}$. Realizou-se ensaios nas concentrações de 20 e $40 \%$ em peso de ácido sulfúrico, com tempos de contato de 120 e $210 \mathrm{~min}$, tempos esses marcados após a dispersão atingir a temperatura de $90{ }^{\circ} \mathrm{C}$. No final de cada experimento, o material foi filtrado a vácuo imediatamente após a tempo de ataque e lavado com água destilada até não se observar reação de sulfatos com cloreto de bário, nos filtrados. Posteriormente, a amostra foi posta para secar a $55^{\circ} \mathrm{C}$. Após seca, foi desagregada e passada em peneira 200 mesh. As amostras ativadas foram denominadas de K20/120, K40/120, K20/210 e K40/210.

\subsection{Ensaio de descoramento}

A amostra de argila comercial utilizada como referência e a amostra de óleo de soja neutralizado e seco foram obtidas da empresa Santista-Ceval de Gaspar/SC - Brasil. $\mathrm{O}$ ensaio foi realizado sob agitação mecânica usando-se $0,8 \%$ de amostra de argila em relação ao peso do óleo de soja neutralizado. A temperatura de ensaio foi de $100{ }^{\circ} \mathrm{C} \mathrm{e}$ o tempo de contato foi de $30 \mathrm{~min}$. O sistema foi mantido sob atmosfera inerte (nitrogênio) e pressão absoluta de $310 \mathrm{mmHg}$. Após, o óleo foi imediatamente separado da argila por filtração a vácuo. O ensaios foram realizados com o material no estado natural e com os obtidos após ativação ácida. Testou-se também nas mesmas condições, como referência, uma argila ativada usada industrialmente no descoramento de óleo de soja: Fulmont Premiere. A capacidade de descoramento foi determinada pela medida da absorbância dos óleos, em um espectrofotômetro digital WFJ525-W(724) UV-visível, no comprimento de onda de máxima absorbância do óleo neutralizado: $440 \mathrm{~nm}$.

\subsection{Técnicas de caracterização}

Para a caracterização dos materiais, usou-se as técnicas de análise térmica diferencial (DTA) e termogravimétrica (TG), infravermelho (IR) e análise química (AQ). As curvas DTA/TG foram obtidas utilizando um analisador térmico Netzsch STA 409 com uma razão de aquecimento de $10{ }^{\circ} \mathrm{C} / \mathrm{min}$, operando em atmosfera de ar seco $(35 \mathrm{~mL} / \mathrm{min})$, na faixa de temperatura de 25 $1000{ }^{\circ} \mathrm{C}$. A análise química foi determinada por flourescência de raios-X com o uso do instrumento Philips PW-2400. Os espectros de infravermelho foram obtidos utilizando um equipamento FT Perkin Elmer 16PC, com medidas de comprimento de onda de 4000 a $400 \mathrm{~cm}^{-1}$. O teor de magnésio interlamelar foi determinado pelo método do acetato de amônio ${ }^{10}$.

\section{Resultados e Discussão}

O tratamento ácido modificou a composição estrutural da bentonita como pode-se observar através das mudanças ocorridas nas análises químicas na Tabela 1. O teor de magnésio octaédrico $\left(\mathrm{MgO}_{\text {oct }}\right)$ presente na amostra original foi calculado pela diferença entre o teor total na amostra original $\left(\mathrm{MgO}_{\mathrm{t}}: 1,56\right)$ e o teor de $\mathrm{MgO}$ interlamelar $(0,05)$, determinado pelo método do acetato de amônio. Nas amostras ativadas, o MgO interlamelar foi extraído e os resultados obtidos pela AQ (ver Tabela 1) correspondem ao $\mathrm{MgO}_{\text {oct. }}$ Os cátions trocáveis $\mathrm{Na}^{+}, \mathrm{K}^{+}$e $\mathrm{Ca}^{2+}$ devem ter sido removidos pelo tratamento ácido e suas quantidades que permaneceram nas amostras ativadas foram consideradas correspondentes à impurezas inertes ao tratamento $^{18}$. A ativação ácida origina um material com maior conteúdo de sílica e pode-se observar também uma significativa remoção de cátions localizados em posição

Tabela 1. Composição química das amostras (\% de óxidos, em peso).

\begin{tabular}{lcccccccccccc}
\hline Amostra & $\mathrm{SiO}_{2}$ & $\mathrm{Al}_{2} \mathrm{O}_{3}$ & $\mathrm{MgO}_{\mathrm{t}}$ & $\mathrm{MgO}_{\text {oct }}$ & $\mathrm{Fe}_{2} \mathrm{O}_{3}$ & $\mathrm{TiO}_{2}$ & $\mathrm{CaO}$ & $\mathrm{K}_{2} \mathrm{O}$ & $\mathrm{MnO}$ & $\mathrm{Na}_{2} \mathrm{O}$ & $\mathrm{r}$ \\
\hline $\mathrm{K}$ (natural) & 69,53 & 15,58 & 1,56 & 1,51 & 3,49 & 0,55 & 0,65 & 1,23 & 0,09 & 2,70 & 3,38 \\
$\mathrm{~K} 20 / 120$ & 75,37 & 13,25 & 1,11 & 1,11 & 2,10 & 0,54 & 0,33 & 1,10 & 0,01 & 0,79 & 4,58 \\
$\mathrm{~K} 40 / 120$ & 75,81 & 12,78 & 1,07 & 1,07 & 2,01 & 0,53 & 0,39 & 1,13 & 0,01 & 0,80 & 4,78 \\
$\mathrm{~K} 20 / 210$ & 77,45 & 12,55 & 1,02 & 1,02 & 2,03 & 0,55 & 0,35 & 1,10 & 0,01 & 0,85 & 4,96 \\
$\mathrm{~K} 40 / 210$ & 78,51 & 10,32 & 0,85 & 0,85 & 1,59 & 0,54 & 0,32 & 1,04 & 0,01 & 0,88 & 6,15 \\
\hline
\end{tabular}

r: razão $\mathrm{SiO}_{2} /\left(\mathrm{Al}_{2} \mathrm{O}_{3}+\mathrm{Fe}_{2} \mathrm{O}_{3}+\mathrm{MgO}_{\text {oct }}\right)$. 
octaédrica $\left(\mathrm{Al}_{2} \mathrm{O}_{3}, \mathrm{Fe}_{2} \mathrm{O}_{3}, \mathrm{MgO}_{\text {oct }}\right)$. $\mathrm{O}$ aumento do tempo de tratamento e da concentração de ácido utilizado ocasionam um maior ataque à estrutura, observado pela diminuição da porcentagem dos cátions pertencentes à folha octaédrica $\mathrm{e}$ pelo aumento da relação $\mathrm{SiO}_{2} /\left(\mathrm{Al}_{2} \mathrm{O}_{3}+\mathrm{Fe}_{2} \mathrm{O}_{3}+\mathrm{MgO}_{\text {oct }}\right)$.

A Tabela 2 mostra com maior clareza o efeito do ataque ácido sobre a folha octaédrica da estrutura bentonítica. Nela são mostrados os elementos que constituem tal folha, expressos em moles. Pode-se obsevar a diminuição, em quantidade, de cada cátion após o tratamento ácido sob diferentes condições de concentração e tempo. É importante observar que o tratamento com ácido na concentração $40 \%$ e tempo de contato de 210 min é suficiente para extrair cerca de um terço do total dos cátions que compõem a folha octaédrica.

A curva da análise térmica diferencial (Fig. 1) da bentonita natural sofreu alterações consideráveis com o tratamento ácido. $\mathrm{O}$ primeiro pico endotérmico das bentonitas ativadas, que corresponde à perda de água interlamelar, é menos intenso e mais largo. Esse pico é fortemente dependente dos cátions em posição de troca. Com a ativação, esses cátions foram removidos e o próton do ácido prevalece nessa posição, provavelmente em conjunto com os cátions que foram removidos da folha octaédrica, que em certas circunstâncias ficam localizados em posição de troca ${ }^{8}$. Os picos endotérmicos localizados na zona de $500-700{ }^{\circ} \mathrm{C}$ na amostra original, correspondentes à perda de hidroxilas, se modificam notavelmente com o tratamento ácido, sendo que nas bentonitas tratadas, esses picos ocorrem a temperaturas menores e com diminuição na intensidade, tornando o material mais sensível às variações térmicas.

As curvas termogravimétricas ilustradas na Fig. 2 indicam que a diferença entre a amostra natural e as tratadas está na perda de massa decorrente da desidroxilação da estrutura que ocorre próximo a $600{ }^{\circ} \mathrm{C}$, já que na amostra natural a curva é mais pronunciada e que nas amostras tratadas se observa uma perda contínua que começa a menores temperaturas, o que corrobora os resultados da análise térmica diferencial na Fig. 1.

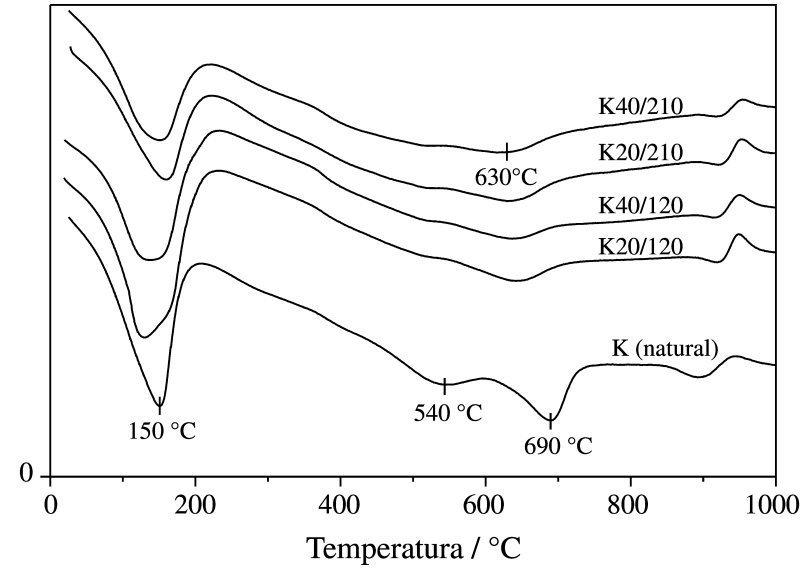

Figura 1. Curvas DTA das amostras natural e ativadas.

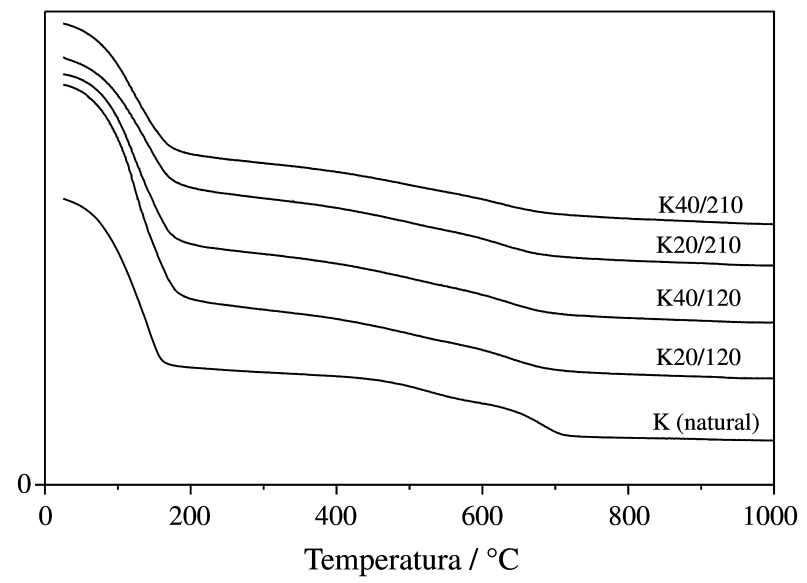

Figura 2. Curvas TG das amostras natural e ativadas.

Os valores da perda de massa (\%) decorrentes da desidroxilação da amostra natural e das ativadas foram calculados a partir das curvas TG (Fig. 2). O intervalo de temperatura analisado foi: temperatura inicial de $450{ }^{\circ} \mathrm{Ce}$ temperatura final de $750{ }^{\circ} \mathrm{C}$. Os valores são apresentados na Tabela 3, bem como a porcentagem de destruição da folha octaédrica, provocada pelo ataque ácido, calculada pela diminuição da perda de peso no intervalo de temperaturas de desidroxilação, com relação à perda sofrida nessa região pela amostra não ativada. Todas as amostras tratadas

Tabela 2. Remoção de cátions octaédricos $\left(\mathrm{Al}^{3+}, \mathrm{Mg}^{2+} \mathrm{e} \mathrm{Fe} e^{2+/ 3+}\right)$.

\begin{tabular}{lccccc}
\hline Amostra & $\begin{array}{c}\mathrm{Al}^{3+} \\
(\mathrm{mol})\end{array}$ & $\begin{array}{c}\mathrm{Mg}^{2+} \\
(\mathrm{mol})\end{array}$ & $\begin{array}{c}\mathrm{Fe}^{2+/ 3+} \\
(\mathrm{mol})\end{array}$ & $\begin{array}{c}\text { Soma dos cátions } \\
(\mathrm{mol})\end{array}$ & $\begin{array}{c}\text { Total de cátions } \\
\text { extraídos }(\%)\end{array}$ \\
\hline $\mathrm{K}($ natural $)$ & 0,305 & 0,037 & 0,044 & 0,386 & 0,00 \\
$\mathrm{~K} 20 / 120$ & 0,259 & 0,027 & 0,026 & 0,312 & 19,17 \\
$\mathrm{~K} 40 / 120$ & 0,250 & 0,026 & 0,025 & 0,301 & 22,02 \\
$\mathrm{~K} 20 / 210$ & 0,246 & 0,025 & 0,025 & 0,296 & 23,31 \\
$\mathrm{~K} 40 / 210$ & 0,202 & 0,021 & 0,020 & 0,243 & 37,05 \\
\hline
\end{tabular}


Tabela 3. Porcentagem de destruição da folha octaédrica, calculadas a partir das curvas TG.

\begin{tabular}{lcc}
\hline Amostra & $\begin{array}{c}\text { \% de perda de massa } \\
\text { na desidroxila- } \\
\text { ção, faixa: } 450-750{ }^{\circ} \mathrm{C}\end{array}$ & $\begin{array}{c}\text { \% calculada de } \\
\text { destruição da folha } \\
\text { octaédrica }\end{array}$ \\
\hline $\mathrm{K}$ (natural) & 2,69 & 0,00 \\
$\mathrm{~K} 20 / 120$ & 2,24 & 16,73 \\
$\mathrm{~K} 40 / 120$ & 2,11 & 21,56 \\
$\mathrm{~K} 20 / 210$ & 2,08 & 22,67 \\
$\mathrm{~K} 40 / 210$ & 1,80 & 33,08 \\
\hline
\end{tabular}

apresentam de 17 a $30 \%$ da folha octaédrica destruída, o que evidencia que mesmo sob drásticas condições de ataque (por exemplo, concentração de $40 \%$ com 210 minutos), suas estruturas não são totalmente destruídas.

Os espectros de IR (Fig. 3) também indicam modificações estruturais da bentonita ocasionadas pelo processo de ativação ácida. Apesar de as bandas referentes às uniões dos átomos continuarem presentes após o tratamento ácido, pode-se observar mudanças em suas intensidades. As alterações mais notáveis podem ser observadas nas bandas localizadas em $465 \mathrm{~cm}^{-1}$ ( $\mathrm{Si}-\mathrm{O}$ $\mathrm{Si}), 525 \mathrm{~cm}^{-1}$ (Si-O-Al), $3450 \mathrm{~cm}^{-1}\left(\mathrm{H}_{2} \mathrm{O}\right.$ interlamelar) e a $3640 \mathrm{~cm}^{-1}(\mathrm{Mg}-\mathrm{OH}-\mathrm{Al})$.

O poder descorante das bentonitas natural e ativadas, bem como da amostra utilizada como referência é mostrado na Tabela 4. As amostras ativadas com concentração de $40 \%$ e as amostras com tempo de contato de 210 min para ambas as concentrações (20 e $40 \%$ ) originam um grau de descoramento superior a $80 \%$, obtendo-se assim materiais adsorventes com poder descorante comparável e superior ao de um produto comercial utilizado nas indústrias de refino de óleos.

As principais alterações estruturais ocorridas após ataque ácido da bentonita, observadas pelas diferentes técnicas de análise (química, térmica e por infravermelho), são apresentadas na Tabela 5, juntamente com os resultados da capacidade de descoramento de óleo de

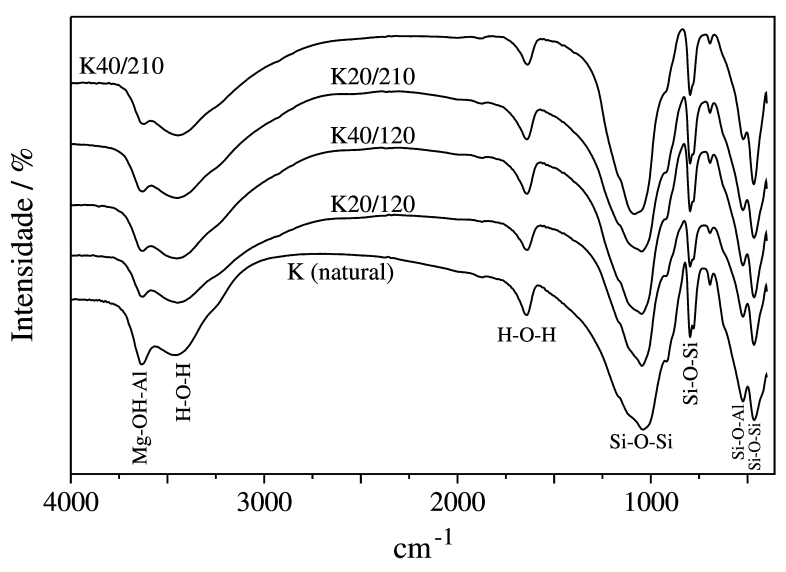

Figura 3. Espectros de IR das amostras natural e ativadas.

Tabela 4. Eficiência das bentonitas no descoramento do óleo de soja.

\begin{tabular}{lc}
\hline Material & GD (\%) ${ }^{1}$ \\
\hline Óleo de soja sem amostra & 0,00 \\
Óleo tratado com amostra K (natural) & 9,99 \\
Óleo tratado com amostra K20/120 & 61,97 \\
Óleo tratado com amostra K40/120 & 80,46 \\
Óleo tratado com amostra K20/210 & 83,21 \\
Óleo tratado com amostra K40/210 & 88,56 \\
Óleo tratado com amostra referência & 84,56 \\
(Fulmont Premiere) & \\
\hline
\end{tabular}

${ }^{1} \mathrm{GD}$ (Grau de Descoramento) $(\%)=\left[\left(\mathrm{A}_{0}-\mathrm{A}\right) / \mathrm{A}_{0}\right]$ x 100, onde "A 0 " é a absorbância do óleo neutralizado e seco (antes do descoramento) e "A" é a absorbância do óleo descorado.

soja. Observa-se que o grau de descoramento aumenta à medida que se vai extraindo os cátions octaédricos da estrutura da bentonita. $\mathrm{O}$ aumento da capacidade da bentonita no descoramento do óleo pode ser observado também com o aumento da porcentagem de destruição da folha octaédrica. O grau de descoramento aumenta com a diminuiçãodarazãoSi-O-Al/Si-O-Si,indicandoqueoataque ácido vai removendo o cátion $\mathrm{Al}$ e aumentando o poder clarificante da argila.

Tabela 5. Resultados das mudanças estruturais decorrentes do ataque ácido e o grau de descoramento do óleo.

\begin{tabular}{lcccc}
\hline Amostra & $\begin{array}{c}\text { \% de destruição da folha } \\
\text { octaédrica (TG) }\end{array}$ & $\begin{array}{c}\text { \% de cátions extraídos } \\
(\text { AQ) }\end{array}$ & $\begin{array}{c}\text { *Razão Si-O-Al/ Si-O- } \\
\text { Si (IR) }\end{array}$ & $\begin{array}{c}\text { Grau de descoramento } \\
(\%)\end{array}$ \\
\hline K(natural) & 0,00 & 0,00 & 0,44 & 9,99 \\
K20/120 & 16,73 & 19,17 & 0,31 & 61,97 \\
K40/120 & 21,56 & 22,02 & 0,26 & 80,46 \\
K20/210 & 22,67 & 23,31 & 0,28 & 83,21 \\
K40/210 & 33,08 & 37,05 & 0,13 & 88,56 \\
\hline
\end{tabular}

*Razão entre a intensidade das bandas localizadas em $525 \mathrm{~cm}^{-1}$ (Si-O-Al) e $465 \mathrm{~cm}^{-1}$ (Si-O-Si), obtida a partir dos espectros de IR na Fig. 3. 


\section{Conclusões}

$\mathrm{O}$ ataque à estrutura da bentonita pela ação do ácido sulfúrico é fortemente dependente da concentração ácida e do tempo de ativação.

As mudanças estruturais observadas por AQ, DTA-TG e IR indicam que a alteração da folha octaédrica é sensível ao ataque ácido.

A remoção de $37 \%$ dos cátions octaédricos, causada pelo ataque com ácido sulfúrico à bentonita argentina, originou um adsorvente altamente eficiente no descoramento de óleo de soja, apresentando poder descorante superior ao da argila comercial utilizada na indústria de refino de óleos vegetais.

\section{Agradecimentos}

À Capes, pelo auxílio financeiro a um dos autores (E.L.F.).

Ao Centro de Tecnologia em Cerâmica (CTC), Criciúma/SC - Brasil, pelas análises químicas.

À Susana Conconi do Centro de Tecnología de Recursos Minerales y Cerámica (Argentina), pela realização das análises DTA-TG.

\section{Referências}

1.Prakash, K.; Jasra, R.V.; Bhat, T.S.G. Evolution of porosity and surface acidity in montmorillonite clay on acid activation, Ind. Eng. Chem. Res., v. 34, p. 1440-1448, 1995.

2. Mokaya, R.; Jones, W. Pillared clays and pillared acid-activated clays: a comparative study of physical, acidic and catalytic properties, J. Catal., v. 153, p. 76-85, 1995.

3. Findik, S.; Gündüz, G. Isomerization of $\alpha$-pinene to camphene, J. Am. Oil Chem. Soc., v. 74, n. 9, p. 1145-1151, 1997.

4. Clarke, G.M. Special Clays, Ind. Miner., v. 216, p. 25-51, 1985.

5. O'Driscoll, M. Bentonite: overcapacity in need of markets, Ind. Miner., v. 250, p. 43-67,1988.

6. Santarem, J. European market developments for absorvent clays, Ind. Miner., v. 304, p. 35-47, 1993.

7.Christidis, G.E.; Scott, P.W.; Dunham, A.C. Acid activation and bleaching capacity of bentonites from the islands of Milos and Chios, Aegean, Greece, Appl. Clay Sci., v. 12, p. 329-347, 1997.
8. Volzone, C.; López, J.M.; Pereira, E. Activación ácida de un material esmectítico, Rev. Latinoam. Ing. Quím. Quím. Apl., v. 16, p. 205-215, 1986.

9. Volzone, C.; Zalba, P.E.; Pereira, E. Activación ácida de esmectitas: II. Estudio mineralógico, An. Asoc. Quím. Argent., v. 76, p. 57-68, 1988.

10. Morgado, A.F. Caracterização e propriedades tecnológicas de uma argila esmectítica de Santa Catarina, Tese de Doutorado, Universidade de São Paulo, São Paulo-SP, 1998.

11. Souza Santos, P. Studies on the acid activation of brazilian smectitic clays: A review, International Workshop of Activated Clays, Proceedings, La Plata, Argentina, p. 21-31, 1998.

12. Srasra, F.; Bergaya, H.; van Damme, H.; Ariguib, N.K. Surface properties of an activated bentonite Decolorisation of rape-seed oils, Appl. Clay Sci., v. 4, p. 411-421, 1989.

13. Díaz, F.R.V.; Souza Santos, P. Efeito do ataque ácido, da ordem de adição dos reagentes e do tipo de cátion interlamelar em esmectitas. I - Distribuição de poros por porosimetria de mercúrio, Cerâmica, v. 37, n. 249, p. 70-75, 1991.

14. Foletto E.L.; Volzone, C.; Morgado, A.F.; Porto, L.M. Modificação estrutural de bentonitas e sua utilização como agente descorante, IV Coloquio Latinoamericano de Fractura y Fatiga, Neuquén, Argentina, CD ROM, p. 1081-1086, 2000.

15.Foletto, E.L.; Volzone, C.; Morgado, A.F.; Porto, L.M. Análise comparativa da ativação ácida de dois materiais argilosos com diferentes composições mineralógicas, VI Jornadas Argentinas de Tratamiento de Minerales, Salta, Argentina, p. 43-48, 2000.

16. Grim, R.E. Applied Clay Mineralogy, McGraw-Hill, New York, 442 p., 1962.

17. Tkac, I.; Komadel, P.; Müller, D. Acid treated montmorillonites: A study ${ }^{29} \mathrm{Si}$ e ${ }^{27}$ Al MAS-NMR, Clay Miner., v. 29, p. 11-19, 1994.

18. Kaviratna, H.; Pinnavaia, T. Acid hydrolysis of octahedral $\mathrm{Mg}^{2+}$ sites in 2:1 layered silicates: An assessment of edge attack and gallery acess mechanisms, Clays Clay Miner., v. 42, p. 717-723, 1994.

19. Barrios, M.S.; Gonzáles, L.V.F.; Rodríguez, M.A.V.; Pozas, J.M.M. Acid activation of a palygorskite with $\mathrm{HCl}$ : development of physico-chemical, textural and surface properties. Applied Clay Science, v. 10, p. 247-258, 1995. 